\title{
Uveitis Subtypes in a German Interdisciplinary Uveitis Center - Analysis of 1916 Patients
}

\author{
EVA JAKOB, MIRJAM S. REULAND, FRIEDERIKE MACKENSEN, NADINE HARSCH, MONIKA FLECKENSTEIN, \\ HANNS-MARTIN LORENZ, REGINA MAX, and MATTHIAS D. BECKER
}

\begin{abstract}
Objective. Studies on the epidemiology of uveitis are rare and cohorts are small. We analyzed the frequencies of classified forms of uveitis in all patients at our center.

Methods. We studied 1916 consecutive patients with inflammatory eye disease. Data were analyzed regarding associated systemic disease, infection, ocular syndromes, anatomic localization, age, and sex.

Results. In $59.1 \%$ of patients, a classified form of uveitis was observed: associated systemic diseases in $43.7 \%$, the most frequent ones sarcoidosis $(17.4 \%)$ and ankylosing spondylitis (16.8\%); ocular syndromes in $34.3 \%$, the most frequent HLA-B27-positive anterior uveitis (AU; 35.1\%) and Fuchs uveitis syndrome (FUS; $34.3 \%$ ); and infections in $22.4 \%$, the most frequent herpetic infections $(46.1 \%)$ and toxoplasmosis $(31.5 \%)$. We found AU in $45.4 \%$ of patients (15.4\% HLA-B27-positive AU and $11.3 \%$ FUS), intermediate uveitis in $22.9 \%$ (unclassified $53.7 \%$ and multiple sclerosis $10.3 \%$ ), and posterior uveitis in $13.5 \%$ (24.7\% toxoplasmosis). Panuveitis was diagnosed in $6.2 \%$ of cases (Behçet's disease 12.6\%; sarcoidosis 10.9\%). The remaining $12.0 \%$ of cases showed extrauveal manifestations (scleritis, episcleritis, keratitis, optic neuritis, myositis, and orbital inflammation).

Conclusion. We describe the largest cohort to date of consecutive patients from a specialized uveitis center. The high frequency of classified disease, nearly $60 \%$ in our clinic, shows the usefulness of an interdisciplinary approach, oriented on anatomic presentation. (First Release Dec 15 2008; J Rheumatol 2009;36:127-36; doi:10.3899/jrheum.080102)
\end{abstract}

Key Indexing Terms:

UVEITIS EPIDEMIOLOGY DIAGNOSIS OCULAR INFLAMMATION

Uveitis, the term used for intraocular inflammation of the uvea, is responsible for $5 \%-20 \%$ of cases of legal blindness and $10 \%$ of severe visual disorders in the developed nations ${ }^{1-7}$. Frequently, the diagnosis of uveitis conceals ocular involvement related to a systemic disease, an infection, or an ocular syndrome. The specific diagnosis of the underlying disease is difficult to determine and requires interdisciplinary cooperation. Often rheumatologists are asked by an ophthalmologist to "investigate" a patient with uveitis for a rheumatic disease, which is a challenge for the rheumatologist, as uveitis is one diagnosis with heterogeneous subsets

From the Interdisciplinary Uveitis Center, University Eye Hospital; and the Interdisciplinary Uveitis Center, Department for Internal Medicine V, University of Heidelberg, Heidelberg, Germany.

Dr. Jakob and Dr. Reuland contributed equally to this report.

E. Jakob, MD; M.S. Reuland, MD, Resident; F. Mackensen, MD, Ophthalmologist; N. Harsch, MD, Resident; M. Fleckenstein, MD, Resident, Interdisciplinary Uveitis Center, University Eye Hospital; H. Lorenz, MD, Professor of Rheumatology; R. Max, MD,

Rheumatologist, Interdisciplinary Uveitis Center, Department for Internal Medicine V; M.D. Becker, Professor of Ophthalmology, Interdisciplinary Uveitis Center, University Eye Hospital.

Address reprint requests to Dr. F. Mackensen, Interdisciplinary Uveitis Center, University Eye Hospital, INF 350, Heidelberg 69120, Germany. Email: Friederike.Mackensen@uveitiszentrum.de

Accepted for publication August 29, 2008. that correspond to many diseases ${ }^{8}$. Extensive and costly laboratory and imaging diagnostics are often ordered without giving any result. In order to diagnose associated conditions and recognize treatment necessities without squandering healthcare resources, knowledge of the epidemiology of uveitis is essential. However, studies on the epidemiology of uveitis are rare and usually include small cohorts; and the results are controversial, due to differences in numbers of study participants, geography, quality of classification system, and patient selection.

Progress has been made in recognizing, diagnosing, and classifying uveitis and associated systemic disease. Thus, older epidemiologic studies have their limitations. A precise analysis makes possible an effective approach that incorporates likelihoods of associated diagnoses depending on anatomic localization and patient's sex and age group. We describe the biggest cohort of patients with uveitis from one tertiary referral center published to date, and illustrate the usefulness of this diagnostic approach.

\section{MATERIALS AND METHODS}

We performed a retrospective analysis of the medical records of all patients who presented to the Interdisciplinary Uveitis Center at the University of Heidelberg between October 2001 and October 2006. Inclusion criteria were a diagnosis of uveitis, or extrauveal disease as defined below. 
Exclusion criteria were masquerade syndromes (ocular irritation after surgery, trauma, retinal detachment, posterior vitreous detachment, vitreous hemorrhage, or malignancies).

Each patient received an ophthalmologic examination, consisting of visual acuity recordings, slit-lamp examination, tonometry, and indirect ophthalmoscopy. Diagnoses and anatomic classification of uveitis were based on SUN workshop and International Uveitis Study Group criteria ${ }^{9,10}$.

For diagnosis of associated diseases a detailed medical history and clinical examination by a rheumatologist were undertaken, and basic tests consisting of blood cell count, chemistry, serum fluorescent treponemal antibody absorption detection, serologic tests for Lyme disease, and chest radiographs were performed. Subsequent tests were ordered depending on suspected associations after interdisciplinary discussions of the case, as described ${ }^{11}$. All findings were entered into a customized electronic database (FileMakerPro ${ }^{\circledR} 7.0$ v2; FileMaker, Inc.) ${ }^{12}$. A final evaluation of each case was done by one ophthalmologist (MDB). If 2 conditions coexisted, the more prominent condition was considered as the main diagnosis, except for a few cases where 2 diagnoses were judged equally likely to be connected with the eye disease.

The term inflammatory eye disease was used for patients with uveitis as well as patients with extrauveal manifestations (scleritis, episcleritis, keratitis, optic neuritis, orbital inflammation, papillitis, neuroretinitis, and myositis). For analysis, we divided these into unclassified or primary versus classified, also called secondary, cases. The term unclassified was used when no associated condition was found despite extensive examination.

Cases of classified disease were divided into 3 groups: systemic disease, ocular syndrome, or infection. Ocular syndromes included a clearly defined uveitis entity without systemic involvement, such as HLA-B27associated anterior uveitis (AU; typical unilateral AU with sudden onset and duration $<3$ months in HLA-B27-positive individuals without joint involvement) or Fuchs uveitis syndrome (FUS; typical low-grade unilateral anterior intermediate uveitis with insidious onset, chronic course, iris transillumination defects or heterochromia, resistant to local or oral prednisone and with later development of cataract and glaucoma). In addition, data were analyzed for anatomic localization, age of onset, and sex. Out of these epidemiologic data we calculated likelihoods for different uveitisassociated diseases that could be helpful to improve the diagnostic process.

\section{RESULTS}

Demographic data. The study included 1916 patients (832 male, 1084 female) with inflammatory eye disease (ratio 0.43:0.57 or $0.77: 1$ ), of which 80 and 150 , respectively, had extrauveal disease. The median age at onset of eye disease was 35 yrs (range 0-90 yrs). The age distribution (Figure 1) shows disease onset less frequently in those of young age and among the elderly. Patients frequenting our Center are from all over Germany, with a focus on the Southwest.

Classified inflammatory eye disease. We found $35.3 \%$ of patients had unclassified and $59.1 \%$ had classified inflammatory eye disease. In $2.4 \%$ of cases, diagnostics were incomplete but classified disease was suspected. A small percentage of patients (3.2\%) were lost to followup before all evaluations had taken place (Figure 2A). Patients with uveal inflammation in particular showed classified disease - 62.4\% (1052/1686), in contrast to those with extrauveal inflammation, where unclassified disease predominated with $56.5 \%(130 / 230)$.

Classified uveitis could be subdivided as follows: associated systemic diseases in $41.8 \%$ (440/1052), ocular syndromes in $36.9 \%$ (388/1052), and infection in $22.0 \%$ (231/1052). Five patients were diagnosed with 2 systemic diseases that were possibly linked to their eye disease. In 2 patients an infection with 2 different agents was diagnosed and one patient had 2 ocular syndromes. Another 5 patients were diagnosed with 2 diagnoses out of different groups, e.g., a systemic disease and an infection.

Uveitis and associated systemic disease, ocular syndromes, and infectious conditions. The most frequent forms of classified uveitis in our clinic are shown in Table 1 and Figure 2B. Among the 440 cases of uveitis with associated systemic disease, sarcoidosis $(82 / 440,18.6 \%)$ and ankylosing spondylitis (AS; 83/440, 18.9\%) were the most frequent (Table 2).

Of the 388 cases of uveitis with an ocular syndrome, the most frequent ones were HLA-B27-positive AU (136/388, $35.1 \%)$ and FUS $(133 / 388,34.3 \%$; Table 3$)$. FUS is a mild, chronic inflammation restricted solely to the eye, which has a typical clinical presentation often with heterochromia and does not need immunosuppressive therapy.

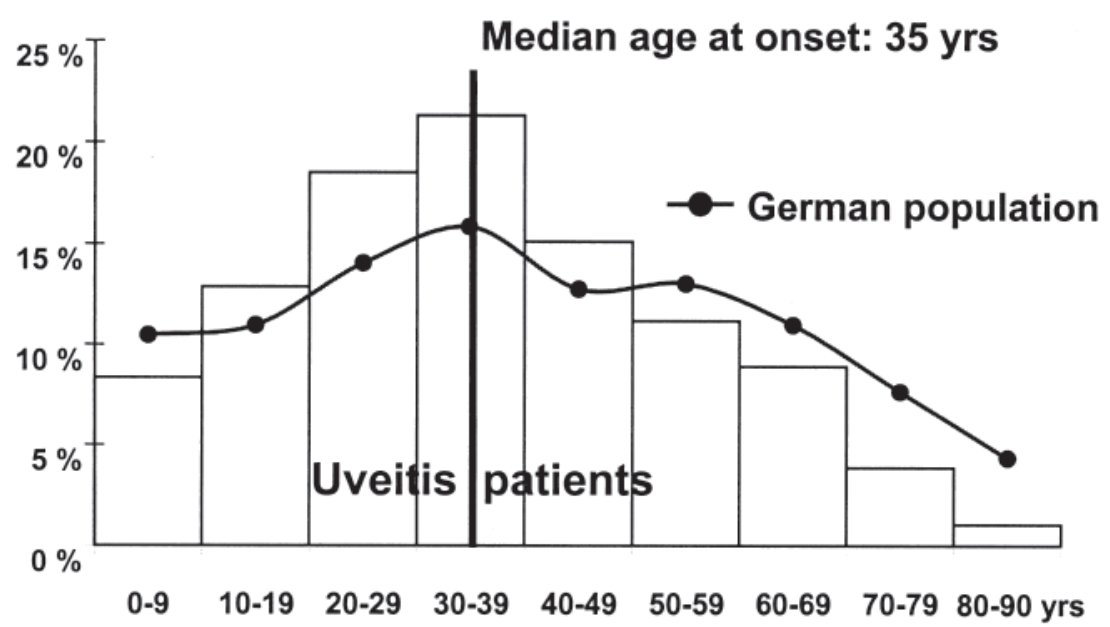

Figure 1. Age distribution at onset of uveitis manifestations in comparison to the German population pyramid (source: Statistisches Bundesamt ${ }^{47}$ ). 


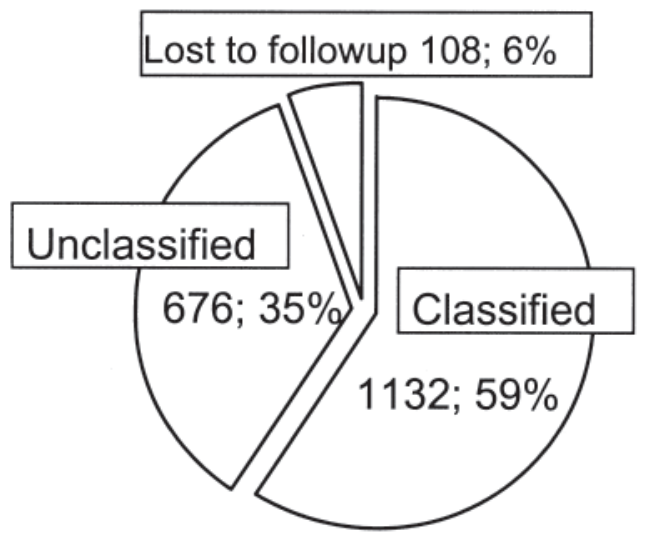

Figure 2A. Ratio of classified and unclassified inflammatory eye disease.
Among the 231 cases of uveitis associated with an infectious condition, the most frequent were herpetic infections (99/231, 42.9\%) and toxoplasmosis (80/231, 34.6\%; Table 4). Anatomic localization. AU was found in $45.4 \%$ of patients (870/1916), intermediate uveitis in $22.9 \%$ (438/1916), and posterior uveitis in $13.5 \%(259 / 1916)$. Panuveitis was found in $6.2 \%$ of cases $(119 / 1916$; Table 5$)$. The remaining $12.0 \%$ of cases were distributed among extrauveal manifestations such as scleritis (107/1916, 5.6\%), episcleritis (40/1916, $2.1 \%)$, keratitis $(33 / 1916,1.7 \%)$, optic neuritis $(18 / 1916$, $0.9 \%)$, orbital inflammation $(12 / 1916,0.6 \%)$, papillitis $(8 / 1916,0.4 \%)$, neuroretinitis $(8 / 1916,0.4 \%)$, and myositis $(2 / 1916,0.1 \%)$.

AU was classified in $69.9 \%$, most frequently HLA-B27-

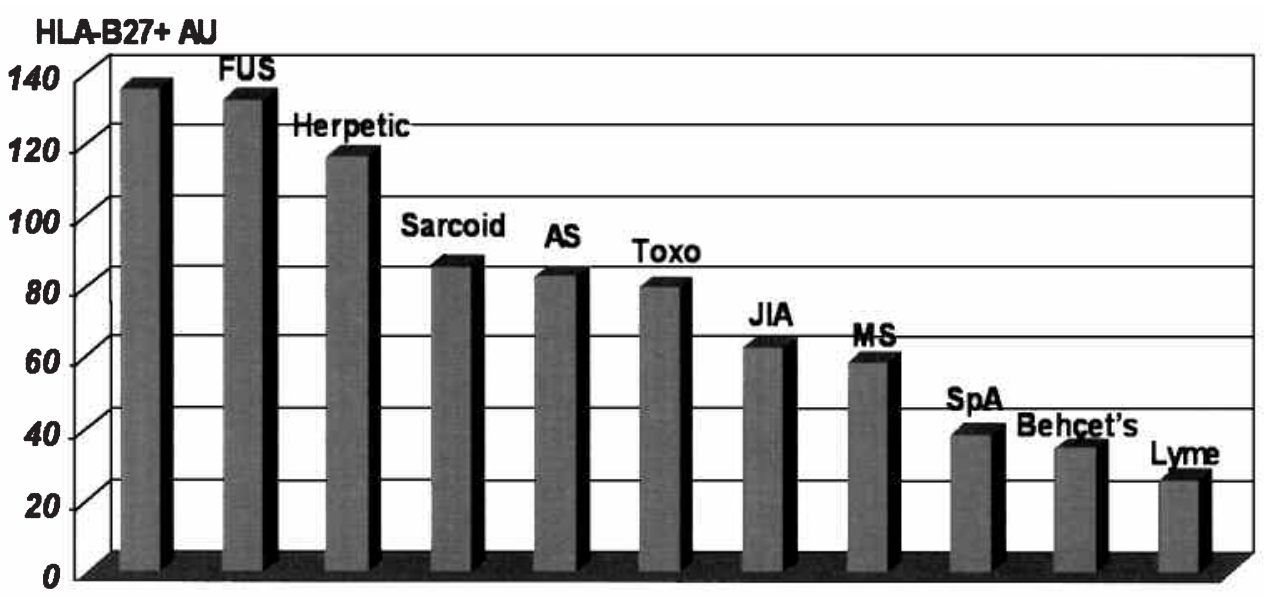

Figure 2B. Most frequent forms of classified uveitis. AU: anterior uveitis; FUS: Fuchs uveitis syndrome; AS: ankylosing spondylitis; Toxo: toxoplasmosis; JIA: juvenile idiopathic arthritis; MS: multiple sclerosis; SpA: spondyloarthropathy.

Table 1. The most frequent associations with inflammatory eye disease in our clinic (percentages do not sum to $100 \%$ due to rounding).

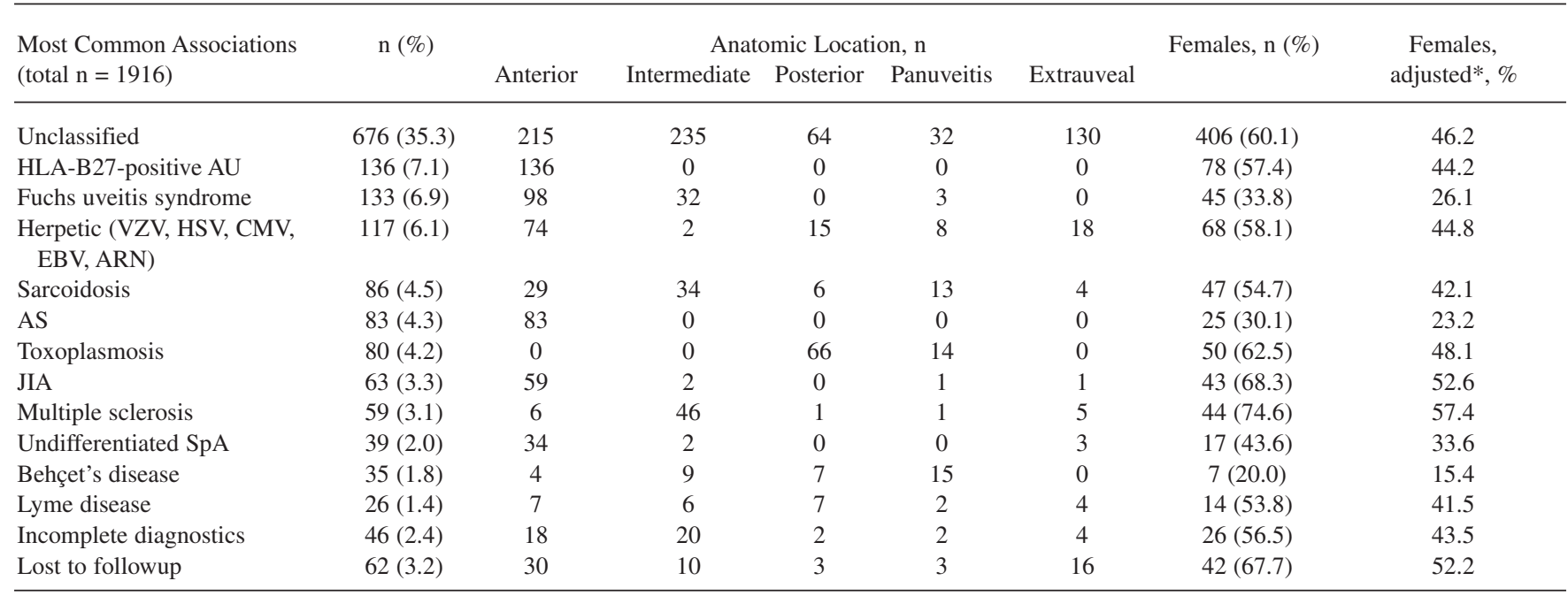

* Percentages were multiplied by 0.77 for appropriate comparison to account for the male:female ratio. AU: anterior uveitis; VZV: varicella zoster virus; HSV: herpes simplex virus; CMV: cytomegalovirus; EBV: Epstein-Barr virus; ARN: acute retinal necrosis; AS: ankylosing spondylitis; JIA: juvenile idiopathic arthritis; SpA: spondyloarthropathy. 
Table 2. Associated systemic diseases in patients with inflammatory eye disease (percentages sum to more than $100 \%$ due to 5 patients with 2 diagnoses).

\begin{tabular}{lccc}
\hline Associated Systemic Disease & $\begin{array}{c}\text { Uveal Manifestation, } \\
\mathrm{n}(\%)(\mathrm{n}=440)\end{array}$ & $\begin{array}{c}\text { Extrauveal manifestation, } \\
\mathrm{n}(\%)(\mathrm{n}=55)\end{array}$ & $\begin{array}{c}\text { Total, } \\
\mathrm{n}(\%)(\mathrm{n}=495)\end{array}$ \\
\hline Sarcoidosis & $82(18.6)$ & $4(7.3)$ & $86(17.4)$ \\
Ankylosing spondylitis & $83(18.9)$ & - & $83(16.8)$ \\
Juvenile idiopathic arthritis & $62(14.1)$ & $1(1.8)$ & $63(12.7)$ \\
Multiple sclerosis & $54(12.3)$ & $5(9.1)$ & $59(11.9)$ \\
Undifferentiated SpA & $36(8.2)$ & $3(5.5)$ & $39(7.9)$ \\
Behçet's disease & $35(8.0)$ & - & $35(7.1)$ \\
Rheumatoid arthritis & $8(1.8)$ & $14(25.5)$ & $22(4.4)$ \\
Ulcerative colitis & $16(3.6)$ & $3(5.5)$ & $19(3.8)$ \\
Crohn's disease & $10(2.3)$ & $6(10.9)$ & $16(3.2)$ \\
Psoriasis arthropathy & $11(2.5)$ & $1(1.8)$ & $12(2.4)$ \\
Reactive arthritis & $11(2.5)$ & $1(1.8)$ & $12(2.4)$ \\
Tubulointerstitial nephritis and uveitis & $10(2.3)$ & - & $10(2.0)$ \\
Acquired immune deficiency syndrome & $8(1.8)$ & - & $8(1.6)$ \\
Wegener's granulomatosis & $3(0.7)$ & $5(9.1)$ & $8(1.6)$ \\
Unclassified systemic vasculitis & $2(0.5)$ & $2(3.6)$ & $4(0.8)$ \\
Vogt-Koyanagi-Harada syndrome & $4(0.9)$ & - & $4(0.8)$ \\
IgA glomerulonephritis & - & $3(5.5)$ & $3(0.6)$ \\
Collagenous diseases & $2(0.5)$ & $1(1.8)$ & $3(0.6)$ \\
Systemic lupus erythematosus & - & $3(5.5)$ & $3(0.6)$ \\
Churg-Strauss syndrome & - & $2(3.6)$ & $2(0.4)$ \\
Polychondritis & $1(0.2)$ & $1(1.8)$ & $2(0.4)$ \\
Sacroiliitis & $2(0.5)$ & - & $2(0.4)$ \\
Sjögren's syndrome & $1(0.2)$ & - & $2(0.4)$ \\
Scleroderma & $2(0.5)$ & - & $2(0.4)$ \\
Autoimmune hepatitis & $1(0.2)$ & & $1(0.2)$ \\
\hline
\end{tabular}

* SpA: spondyloarthropathy.

Table 3. Specific ocular syndromes as a cause of uveitis (percentages sum to more than $100 \%$ due to 1 patient with 2 diagnoses).

\begin{tabular}{lc}
\hline Uveitis with an Ocular Syndrome, $\mathrm{n}=388$ & Total, $\mathrm{n}(\%)$ \\
\hline HLA-B27-positive anterior uveitis* & $136(35.1)$ \\
Fuchs uveitis syndrome & $133(34.3)$ \\
Ocular sarcoidosis** & $22(5.7)$ \\
Multifocal chorioretinitis & $15(3.9)$ \\
Birdshot retinochoroidopathy & $14(3.6)$ \\
Acute posterior multifocal placoid pigment epitheliopathy & $14(3.6)$ \\
Serpiginous chorioretinitis & $12(3.1)$ \\
Punctate inner choroidopathy & $10(2.6)$ \\
Posner-Schlossman syndrome & $10(2.6)$ \\
ANA + chronic anterior uveitis & $6(1.5)$ \\
Multiple evanescent white dot syndrome & $5(1.3)$ \\
Eales' disease & $4(1.0)$ \\
Lens-induced uveitis & $3(0.8)$ \\
Acute zonal occult outer retinopathy & $2(0.5)$ \\
Acute retinal pigment epitheliitis & $2(0.5)$ \\
Acute idiopathic blind spot enlargement syndrome & $1(0.3)$ \\
\hline
\end{tabular}

* An ocular syndrome defined as typical unilateral anterior uveitis with sudden onset and $<3$ months' duration in HLA-B27+ individuals without systemic manifestation of disease. ** A granulomatous intraocular inflammation compatible with sarcoidosis, combined with elevated levels of angiotensin-converting enzyme but normal chest radiographs. positive AU, 15.4\% (134/870) and FUS, 11.3\% (98/870). Counting together all patients with a possible HLA-B27related disease, including those with AS, inflammatory bowel disease, undifferentiated spondyloarthropathy (SpA), reactive arthritis, HLA-B27-positive AU, and psoriatic arthritis, they sum to $32.2 \%$ of cases of AU.

Intermediate uveitis generally was unclassified (235/438, $53.7 \%$ ). In the classified forms, multiple sclerosis was the most frequent - 10.3\% (45/438).

For posterior uveitis, classified forms existed in $71 \%$ of patients. Toxoplasmosis was found most often, with $24.7 \%$ (64/259).

Panuveitis was classified in 68.9\%; Behçet's disease $(15 / 119)$ and sarcoidosis (13/119) were the most frequent diagnoses (12.6\% and $10.9 \%$, respectively).

Uveitis by age distribution and sex. As shown in Figure 1, the very young and the very old were less often affected than the middle aged. The same was true for the classified forms of uveitis; children and the elderly more often showed unclassified uveitis.

For classified uveitis, among the young ( $\leq 16 \mathrm{yrs}$ ), juvenile idiopathic arthritis (JIA) was most frequent, with 
Table 4. Infectious conditions as a cause of inflammatory eye disease (percentages sum to more than $100 \%$ due to 2 patients with 2 diagnoses).

\begin{tabular}{|c|c|c|c|}
\hline Infectious Condition & $\begin{array}{l}\text { Uveal Manifestation, } \\
\text { n }(\%)(\mathrm{n}=231)\end{array}$ & $\begin{array}{c}\text { Extrauveal manifestation, } \\
\mathrm{n}(\%)(\mathrm{n}=23)\end{array}$ & $\begin{array}{c}\text { Total, } \\
\mathrm{n}(\%)(\mathrm{n}=254)\end{array}$ \\
\hline Herpetic infections & 99 (42.9) & $18(78.3)$ & $117(46.1)$ \\
\hline HSV & $40(17.3)$ & $12(52.2)$ & $52(20.5)$ \\
\hline VZV & $39(16.9)$ & $6(26.1)$ & $45(17.7)$ \\
\hline ARN & $10(4.3)$ & & $10(3.9)$ \\
\hline CMV & $8(3.5)$ & & $8(3.1)$ \\
\hline EBV & $2(0.9)$ & & $2(0.8)$ \\
\hline Toxoplasmosis & $80(34.6)$ & & $80(31.5)$ \\
\hline Reactivated & $63(27.3)$ & & $63(24.8)$ \\
\hline Scarred & $12(5.2)$ & & $12(4.7)$ \\
\hline Freshly infected & $5(2.2)$ & & $5(2.0)$ \\
\hline Lyme disease* & $22(9.5)$ & $4(17.4)$ & $26(10.2)$ \\
\hline Tuberculosis & $21(9.1)$ & & $21(8.3)$ \\
\hline Syphilis & $4(1.7)$ & & $4(1.6)$ \\
\hline Toxocariasis & $4(1.7)$ & & $4(1.6)$ \\
\hline Onchocercosis & $2(0.9)$ & & $2(0.8)$ \\
\hline Presumed ocular histoplasmosis syndrome & $1(0.4)$ & & $1(0.4)$ \\
\hline Cat scratch disease & & $1(4.3)$ & $1(0.4)$ \\
\hline
\end{tabular}

\footnotetext{
* Lyme disease was diagnosed by positive IgG and confirmed by specific bands in Western blot, but not all patients needed antibiotic treatment. Southern Germany has a high seroprevalence for Borreliae, which makes interpretation of serology results difficult. Thus, these results in regard to uveitis must be regarded with caution. VZV: varicella zoster virus; HSV: herpes simplex virus; CMV: cytomegalovirus; EBV: Epstein-Barr virus; ARN: acute retinal necrosis.
}

25.3\%. Between ages 17 and 29, HLA-B27-positive AU and FUS were most frequent (12.4\% and 9.7\%). Among middle aged patients (30-65 yrs), a variety of syndromes were found in comparable frequencies: HLA-B27-positive AU $7.9 \%$, AS 5.5\%, herpetic infection 5.3\%, sarcoidosis $4.4 \%$, FUS $4.9 \%$, and multiple sclerosis $3.3 \%$. In patients older than 65 years, however, uveitis associated with a herpes infection predominated $(15.1 \%)$. In regard to the herpetic infections, it is necessary to know that often the diagnoses were made clinically and not always verified by polymerase chain reaction testing of aqueous fluid. Most herpetic infections were caused by herpes simplex virus $(n=52)$, followed by varicella zoster virus $(n=45)$, cytomegalovirus $(\mathrm{n}=8)$, and Epstein-Barr virus $(\mathrm{n}=2)$.

The male:female ratio of 0.43:0.57 in the whole cohort was similar in the group with classified uveitis (0.47:0.53). Still, several gender preferences could be seen in the subsets of uveitis, even after correction for sex distribution in the cohort (Table 1). Behçet's disease had a strong tendency toward male carriers (84.6\%), as did FUS (73.9\%) and AS (76.8\%), and less so in HLA-B27-positive AU (55.8\%). Multiple sclerosis, however, was more frequent in women $(57.4 \%)$. Birdshot choroidopathy was clearly more frequent in female patients $(71.5 \%)$. JIA was diagnosed slightly more often in girls, with $52.6 \%$.

Calculation of associated diseases subject to different uveitis patterns. To show the importance of knowledge of epidemiologic data, we calculated disease likelihoods for the most important systemic associations and infections. Different uveitis patterns such as those for anatomic local- ization, laterality, age, and sex were attributed to the different diseases. AU, for example, was found to be the strongest risk factor for AS. Any patient at our uveitis center with AU has a risk of $9.5 \%$ for AS. Taking into consideration more pattern information such as alternating laterality, male sex, and adult age, this likelihood increases to $40.1 \%$. But AU is also a high risk factor for herpetic infection. Here the influence of the additional factors unilateral appearance of inflammation and age increase the likelihood to $38.5 \%$. For toxoplasmosis, posterior uveitis was the strongest risk factor (25.5\% for any patient presenting with posterior uveitis). If unilaterality and young age occur as well, the likelihood rises to $68.8 \%$. Further likelihoods for other pattern combinations are presented in Table 6.

\section{DISCUSSION}

Classified and unclassified uveitis. We found a frequency of $59.1 \%$ for classified inflammatory eye disease in our cohort. Only $35.3 \%$ of our patients had unclassified disease as defined above. This corresponds well to the literature for Western Europe and the USA ${ }^{13-19}$. Bodaghi, et $a l^{20}$ found $34 \%$ of unclassified disease in France, Tran, et al ${ }^{18} 28 \%$ in Switzerland, Thean, et $a l^{17} 27 \%$ in Great Britain, and Rodriguez, et $a l^{15} 34.9 \%$ in the US. Banares, et al ${ }^{21}$ found an even higher rate of $66.8 \%$ classified uveitis in Spain. Some older reports or reports from less developed countries gave higher rates of unclassified disease. Palmares, et al ${ }^{22}$ described $48.5 \%$ in Portugal, and Biswas, et $a l^{23}$ found $59.3 \%$ and Singh, et $a l^{24} 51.2 \%$ in India. These numbers might include undiagnosed conditions, due to fewer avail-

Personal non-commercial use only. The Journal of Rheumatology Copyright (C) 2009. All rights reserved. 
Table 5. Anatomic localization of uveitis and most frequent associated causes of uveitis $(\mathrm{n} \geq 5)$.

\begin{tabular}{|c|c|c|c|}
\hline Anterior & Systemic disease $269 / 870$ & Ankylosing spondylitis & $83 / 269$ \\
\hline \multirow[t]{12}{*}{$870 / 1916(45.4 \%)$} & & Juvenile idiopathic arthritis & $59 / 269$ \\
\hline & & Undifferentiated SpA & $34 / 269$ \\
\hline & & Sarcoidosis & $29 / 269$ \\
\hline & & Reactive arthritis & $10 / 269$ \\
\hline & & TINU & $9 / 269$ \\
\hline & & Crohn's Disease & $7 / 269$ \\
\hline & Ocular syndrome $257 / 870$ & HLA-B27+ anterior uveitis & $134 / 257$ \\
\hline & & Fuchs uveitis syndrome & $98 / 257$ \\
\hline & & Posner-Schlossman & $9 / 257$ \\
\hline & & Ocular sarcoidosis & $7 / 257$ \\
\hline & & ANA+ chronic anterior uveitis & $6 / 257$ \\
\hline & Infection $82 / 870$ & Herpes & $74 / 82$ \\
\hline \multirow{3}{*}{$\begin{array}{l}\text { Intermediate } \\
438 / 1916(22.9 \%)\end{array}$} & Ocular syndrome 51/438 & Fuchs uveitis syndrome & $32 / 51$ \\
\hline & & Ocular sarcoidosis & $9 / 51$ \\
\hline & Infection $15 / 438$ & Lyme disease & $6 / 15$ \\
\hline Posterior & Systemic disease $15 / 259$ & Behçet's disease & $7 / 15$ \\
\hline \multirow{8}{*}{$259 / 1916(13.5 \%)$} & & Sarcoidosis & $6 / 15$ \\
\hline & & AIDS & $6 / 15$ \\
\hline & Ocular syndrome $64 / 259$ & APMPPE & $13 / 64$ \\
\hline & & Serpiginous chorioretinitis & $12 / 64$ \\
\hline & & Birdshot retinochoroidopathy & $10 / 64$ \\
\hline & & MCP & $9 / 64$ \\
\hline & & PIC & $7 / 64$ \\
\hline & & MEWDS & $5 / 64$ \\
\hline \multirow{4}{*}{$119 / 1916(6.2 \%)$} & & $\mathrm{MCP}$ & $5 / 16$ \\
\hline & Infection 29/119 & Toxoplasmosis & $14 / 29$ \\
\hline & & Herpes & $8 / 29$ \\
\hline & & Tuberculosis & $5 / 29$ \\
\hline
\end{tabular}

SpA: spondylarthropathy; TINU: tubulointerstitial nephritis and uveitis, ANA: antinuclear antibody, APMPPE: acute posterior multifocal pigment epitheliopathy, MCP: multifocal choroiditis and panuveitis, PIC: puntate inner choroidopathy, MEWDS: multiple evanescent white dot sydnrome.

able diagnostic means. An argument supporting this is an observed decrease in cases of unclassified uveitis in Japan over the years ${ }^{25}$.

Uveitis and associated systemic disease, specific ocular syndromes, and infectious conditions. Among classified uveitis cases, systemic disease was the most frequent association $(25.8 \%)$. The literature reports rates that are somewhat lower $23,26-29$. Such a high rate of systemic associations in our study we believe is due to the interdisciplinary approach of our center, because particular competent knowledge of different disciplines and mutual discussion of findings are helpful in diagnoses of associated diseases.
Specific ocular syndromes affected fewer patients $(20.3 \%)$, and this was reflected in the literature ${ }^{16,25,30}$. The most frequent conditions overall, however, clearly belonged to the category of ocular syndromes. These were FUS and HLA-B27-positive AU.

Although the smallest group among the classified forms is represented by infectious conditions (13.3\%), their diagnostics are especially important because they require completely different therapies. In our cohort, infections were less frequent than in results found by others ${ }^{29-31}$. The literature agreed with our results in that infection most frequently comprised herpetic infections and toxoplasmosis ${ }^{20,27,32}, 2$ 
diseases that can be detected by the ophthalmologist in most cases on the basis of their clinical picture. This does not apply for the next 2 most frequent infections in uveitis patients, Lyme disease and borreliosis, both diseases that require multidisciplinary management.

Among our cases of classified uveitis, the most frequent were HLA-B27-positive AU, FUS, herpetic infection, sarcoidosis, AS, toxoplasmosis, multiple sclerosis, JIA, SpA, Behçet's disease, and Lyme disease (Table 1, Figure 2B). These frequencies compared well with those in the literature (see Tran $e t a l^{18}$ for a review).

Thean, et $a l^{17}$ found frequencies in Great Britain that were similar to ours. Most often, and more so than in most studies including ours, they found HLA-B27-positive AU $(15.2 \%)$ and FUS (13.2\%). Herpes simplex (5.0\%), sarcoidosis $(4.9 \%)$, toxoplasmosis retinitis $(4.6 \%)$, Behçet's disease $(2.4 \%)$, and herpes zoster $(2.3 \%)$ were comparable in frequency.

Tran, et $a l^{18}$ also report HLA-B27-positive AU to be the most frequent, followed by a high rate of herpes zoster (9\%) and toxoplasmosis $(9 \%)$.

Bodaghi, et $a l^{20}$ did not report FUS, herpetic infection, or toxoplasmosis among their most common causes, but instead listed diagnoses such as Vogt-Koyanagi-Harada syndrome (2\%). These are rarely seen in Germany — in our cohort only $0.2 \%$ had this disease. Behçet's disease too was more frequent in their cohort, with $6.1 \%$. Still, they preselected especially severe, chronic forms of uveitis.

Lyme disease did not seem to be as prominent in other studies as in our patient group; this is due to Lyme disease being endemic in Southern Germany, in an environment of high public awareness. It is common that general practitioners initiate laboratory testing for Lyme disease. There is controversy about the interpretation of serology results. We require positive $\mathrm{IgG}$ findings and specific bands in Western blot tests for a diagnosis, but this approach has its limits.

The differences in causes of uveitis reflect regional and genetic factors. For instance, Behçet's disease is rare in the USA and Europe, while it is frequent in countries along the ancient Silk Road. Dutch authors report 1.7\% of Behçet's disease among uveitis patients ${ }^{16}$; in contrast, from Taiwan a much higher $17.9 \%$ is reported ${ }^{33}$.

HLA-B27-associated diseases, in contrast, are more common among Caucasians ${ }^{34}$. HLA-B27-positive AU is more frequent in Northern Europe ${ }^{35}$ than in California ${ }^{14}$ or Italy $^{31}$. Surprisingly, there was also a high count of HLAB27-positive AU in Taiwan ${ }^{33}$.

Uveitis and anatomic localization. Anatomic localization can give useful information to the clinician about the likely cause of uveitis ${ }^{21}$. As in our cohort, with $45.4 \%$, AU is described in the literature as the most common form of uveitis $15,16,18,21,26,28,35$. In general practice it is even more frequent ${ }^{18}$. The most frequent forms of AU in our collective and in the literature are HLA-B27-positive AU and FUS. If the $\mathrm{AU}$ is not explained by an ocular syndrome alone, our data indicate consideration of AS or undifferentiated SpA. Sarcoidosis also appears often as AU, but just as often in an intermediate form.

For intermediate uveitis, our results agree with the literature in that classified forms are rare ${ }^{15,20,36-38}$. If they occur, they represent systemic disease, often multiple sclerosis. Intermediate uveitis is rare in an office of general ophthalmology ( $1 \%$ versus $12 \%$ in a tertiary care center) ${ }^{26}$. We found an even higher percentage, with $22.9 \%$.

Posterior uveitis existed in $13.5 \%$ of our patients, and as reported is most commonly caused by toxoplasmo$\operatorname{sis}^{13,15,27,30,39,40}$. It is found more frequently in tertiary care centers than in general practice $(15 \% \text { versus } 5 \%)^{26}$; the same is true for panuveitis (9\% versus 1\%). Panuveitis is also the rarest uveitis presentation, $6.2 \%$ in our cohort.

In both posterior uveitis and panuveitis associated systemic diseases are rare; sarcoidosis should be considered in both cases. Further, in the case of a posterior inflammation, Behçet's disease should be excluded, especially if the patient comes from a Mediterranean, Arab, or Asian area.

If extrauveal inflammation such as scleritis occurs, the strategy in the search for the associated disease should focus on rheumatoid arthritis (RA), and if there are other corresponding indications on inflammatory bowel diseases.

Uveitis and age and sex distribution. The age distribution in our study population seems representative. Other authors found similar mean ages at uveitis onset of 33 years $^{30}, 34$ years $^{32}, 37$ years $^{15}$, and 44 years $^{29}$. Our observation that uveitis is less common among the young and the elderly is supported by the literature ${ }^{21,30,41}$.

Differences in distribution of uveitis between age groups were found. For children with AU, for example, JIA is a frequent diagnosis ${ }^{42-46}$.

The literature offers some dissent about the male to female ratio in uveitis. Some studies report that more men present with uveitis ${ }^{17,23,24,27}$; some report more women $12,25,30,41$ (range 1.6:1 to $0.7: 1$, respectively). With $0.77: 1$ (or 0.43:0.57), our collective showed a female-oriented ratio. This rate differs from the sex distribution in the general population in Germany, where until age 50 years, men are slightly more numerous $(0.51: 0.49)^{47}$. The specific patterns of distribution in subsets of uveitis by sex are presented in Table 1.

With Table 6 we present an analysis of disease likelihoods depending on various uveitis patterns. These data offer guidance from the ophthalmologic presentation toward a rheumatologic diagnosis and help to facilitate efficient diagnostic testing. In a best-case scenario the ophthalmologic picture can be communicated by the ophthalmologist to the rheumatologist and with the help of these likelihood data, specific testing can take place.

As our study contains such a large number of patients, we were able to calculate the risk of the most important systemic diseases and infections for different pattern combina-

Personal non-commercial use only. The Journal of Rheumatology Copyright @ @ 2009. All rights reserved. 
Table 6. Schematic for diagnosis of the most common systemic associations and underlying infections of uveitis (ocular syndromes are not included because they are diagnosed by the ophthalmologist based on morphologic appearance only). Likelihood of disease: prevalence of disease in the current groups based on pattern considered.

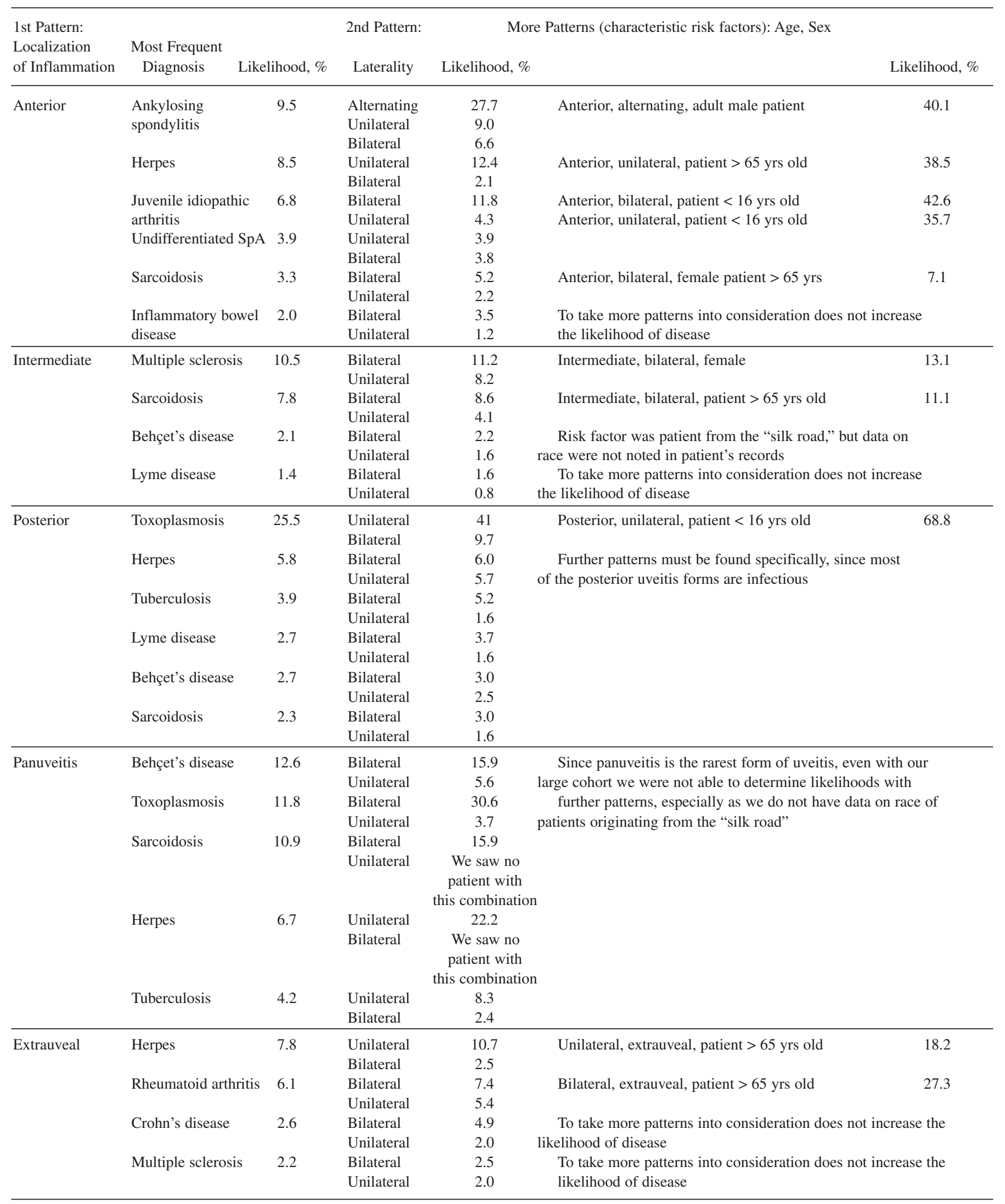


tions on the basis of their prevalences in the different subgroups. It should not go unnoticed that these calculations are based on our specific data and patient cohort. Although the authors consider that these calculations can also be useful in other centers, because as mentioned above, other authors reported similar distributions for most of the underlying diseases. Transmitting our calculations to another center it is naturally necessary to regard the regional and genetic differences in the patient cohort.

Banares, et $a l^{21}$ also calculated disease likelihoods based on uveitis patterns in 407 patients; their calculations for AU are very similar to our results. With our larger study, we can confirm their results for AU. The most likely systemic association for a patient with AU is any form of SpA. Taking into consideration other patterns such as laterality (alternating), sex (male), and age (adult patient) can increase the likelihood up to $40.1 \%$. The most common infection associated with $\mathrm{AU}$ is herpetic infection. Risk-increasing factors are higher age, unilaterality, and the presence of keratouveitis.

In our study, intermediate uveitis was the strongest risk factor for multiple sclerosis, especially in women with bilateral disease, which confers a disease risk of $>13 \%$. This differs from Banares, et al, where only one case of multiple sclerosis is reported; this is due to multiple sclerosis being very rare in $\mathrm{Spain}^{21}$. In their report, sarcoidosis was the most probable underlying disease but Behçet's disease and Lyme disease are also noted. In our study, intermediate uveitis was also a high risk factor for sarcoidois; however, sarcoidosis can occur with various patterns of uveitis and thus should be excluded in every uveitis patient at least by chest radiograph, especially in those with bilateral involvement where the risk is generally higher for sarcoidosis.

Posterior uveitis is generally a risk factor for an infectious disease, most commonly toxoplasmosis. Further risk for toxoplasmosis is in unilateral involvement at young age; in this case the calculated disease probability amounts to $68.8 \%$. Banares, et $a l^{21}$ reported that unilateral chorioretinitis was associated almost exclusively with toxoplasmosis in their study. But as shown in Table 6, other infections like herpes, tuberculosis, and Lyme disease should be taken into consideration for patients with posterior uveitis.

A patient with panuveitis has a high risk for Behçet's disease (12.6\%), especially if a genetic predisposition is present. This compares closely to the observations of Banares, et $a l^{21}$.

In patients with extrauveal inflammation the authors recommend excluding RA, especially in elderly patients with bilateral inflammation, because nearly every third of this risk group is affected by RA.

We hope that our diagnostic approach following anatomic localization of uveitis and the epidemiologic data given here may recommend specific diagnostic steps in a given patient with uveitis. For the rheumatologist, knowledge of the distribution of different patterns of uveitis is of great value because at least a quarter of all forms of uveitis are associated with a systemic disease that is often hard to detect. The high frequency of $59.1 \%$ of classified uveitis in our cohort reflects the value of this approach.

\section{ACKNOWLEDGMENT}

We thank all residents who added to the database while rotating through our clinic: A. Bauer, A. Reuland, A. Lösch, A. Scheuerle, F. von Weyhe, T. Heger, S. Ebner, D. Miller, M. Pfirrmann, U. Wiehler, G. Varadi, B. Eisert, C. Springer, I. Schmack, S. Bültmann, M. Foerl, J. Wrede, T. Stein, and D. Thiemayer.

\section{REFERENCES}

1. Darrell RW, HP Wagener, Kurland LT. Epidemiology of uveitis. Incidence and prevalence in a small urban community. Arch Ophthalmol 1962;68:502-14.

2. Goldstein H. The reported demography and causes of blindness throughout the world. Adv Ophthalmol 1980;40:1-99.

3. Krumpaszky HG, Klauss V. Cause of blindness in Bavaria. Evaluation of a representative sample from blindness compensation records of Upper Bavaria [German]. Klin Monatsbl Augenheilkd 1992;200:142-6.

4. Makabe R, Hellwig A. Changes in the causes of blindness in recent time [German]. Versicherungsmedizin 1988;40:136-9.

5. Nussenblatt RB. The natural history of uveitis. Int Ophthalmol 1990;14:303-8.

6. Suttorp-Schulten MS, Rothova A. The possible impact of uveitis in blindness: a literature survey. Br J Ophthalmol 1996;80:844-8.

7. ten Doesschate J. Causes of blindness in The Netherlands. Doc Ophthalmol 1982;52:279-85.

8. Rosenbaum JT, Nozik RA. Uveitis: many diseases, one diagnosis. Am J Med 1985;79:545-7.

9. Bloch-Michel E, Nussenblatt RB. International Uveitis Study Group recommendations for the evaluation of intraocular inflammatory disease. Am J Ophthalmol 1987;103:234-5.

10. Jabs DA, Nussenblatt RB, Rosenbaum JT. Standardization of uveitis nomenclature for reporting clinical data. Results of the First International Workshop. Am J Ophthalmol 2005;140:509-16.

11. Becker MD, Rosenbaum JT. Essential laboratory tests in uveitis. Dev Ophthalmol 1999;31:92-108.

12. Bauer AM, Plaza D, Wetter T, Becker MD. Computer-based system for monitoring the course of intraocular inflammation [German]. Ophthalmologe 2005;102:1069-73.

13. Haut J, Roman S, Morin Y, Monin C, Morel C. Search for etiology in 110 cases of uveitis. Value of punctures of the aqueous humor and vitreous body [French]. J Fr Ophtalmol 1995;18:292-304.

14. Henderly DE, Genstler AJ, Smith RE, Rao NA. Changing patterns of uveitis. Am J Ophthalmol 1987;103:131-6.

15. Rodriguez A, Calonge M, Pedroza-Seres M, et al. Referral patterns of uveitis in a tertiary eye care center. Arch Ophthalmol 1996;114:593-9.

16. Smit RL, GS Baarsma, de Vries J. Classification of 750 consecutive uveitis patients in the Rotterdam Eye Hospital. Int Ophthalmol 1993;17:71-6.

17. Thean LH, Thompson J, Rosenthal AR. A uveitis register at the Leicester Royal Infirmary. Ophthal Epidemiol 1996;3:151-8.

18. Tran VT, Auer C, Guex-Crosier Y, Pittet N, Herbort CP. Epidemiological characteristics of uveitis in Switzerland. Int Ophthalmol 1994;18:293-8.

19. Weiner A, BenEzra D. Clinical patterns and associated conditions in chronic uveitis. Am J Ophthalmol 1991;112:151-8.

20. Bodaghi B, Cassoux N, Wechsler B, et al. Chronic severe uveitis: etiology and visual outcome in 927 patients from a single center. Medicine Baltimore 2001;80:263-70.

21. Banares A, Jover JA, Fernandez-Gutierrez B, et al. Patterns of uveitis as a guide in making rheumatologic and immunologic diagnoses. Arthritis Rheum 1997;40:358-70. 
22. Palmares J, Coutinho MF, Castro-Correia J. Uveitis in northern Portugal. Curr Eye Res 1990;9 Suppl:31-4.

23. Biswas J, Narain S, Das D, Ganesh SK. Pattern of uveitis in a referral uveitis clinic in India. Int Ophthalmol 1996;20:223-8.

24. Singh R, Gupta V, Gupta A. Pattern of uveitis in a referral eye clinic in north India. Indian J Ophthalmol 2004;52:121-5.

25. Kotake S, Furudate N, Sasamoto Y, Yoshikawa K, Goda C, Matsuda H. Characteristics of endogenous uveitis in Hokkaido, Japan. Graefes Arch Clin Exp Ophthalmol 1997;235:5-9.

26. McCannel CA, Holland GN, Helm CJ, Comell PJ, Winston JV, Rimmer TG. Causes of uveitis in the general practice of ophthalmology. UCLA Community-Based Uveitis Study Group. Am J Ophthalmol 1996;121:35-46.

27. Mercanti A, Parolini B, Bonora A, Lequaglie Q, Tomazzoli L. Epidemiology of endogenous uveitis in north-eastern Italy. Analysis of 655 new cases. Acta Ophthalmol Scand 2001;79:64-8.

28. Simmons CA, Mathews D. Prevalence of uveitis: a retrospective study. J Am Optom Assoc 1993;64:386-9.

29. Oruc S, Kaplan AD, Galen M, Kaplan HJ. Uveitis referral pattern in a midwest university eye center. Ocul Immunol Inflamm 2003;11:287-98.

30. Soheilian M, Heidari K, Yazdani S, Shahsavari M, Ahmadieh H, Dehghan M. Patterns of uveitis in a tertiary eye care center in Iran. Ocul Immunol Inflamm 2004;12:297-310.

31. Pivetti-Pezzi P, Accortini M, La Cava M, Colabelli Gisoldi RA, Abdulaziz MA. Endogenous uveitis: an analysis of 1417 cases. Ophthalmologica 1996;210:234-8.

32. Islam SM, Tabbara KF. Causes of uveitis at The Eye Center in Saudi Arabia: a retrospective review. Ophthalmic Epidemiol 2002;9:239-49.

33. Chung YM, Yeh TS, Liu JH. Endogenous uveitis in Chinese - an analysis of 240 cases in a uveitis clinic. Jpn J Ophthalmol 1988;32:64-9.

34. Baarsma GS. The epidemiology and genetics of endogenous uveitis: a review. Curr Eye Res 1992;11 Suppl:1-9.
35. Rothova A, Buitenhuis HJ, Meenken C, et al. Uveitis and systemic disease. Br J Ophthalmol 1992;76:137-41.

36. Gritz DC, Wong IG. Incidence and prevalence of uveitis in Northern California; the Northern California Epidemiology of Uveitis Study. Ophthalmology 2004;111:491-500.

37. Aaberg TM. The enigma of pars planitis. Am J Ophthalmol 1987;103:828-30.

38. Deane JS, Rosenthal AR. Course and complications of intermediate uveitis. Acta Ophthalmol Scand 1997;75:82-4.

39. Paivonsalo-Hietanen T, Tuominen J, Vaahtoranta-Lehtonen H, Saari KM. Incidence and prevalence of different uveitis entities in Finland. Acta Ophthalmol Scand 1997;75:76-81.

40. Perkins ES, Folk J. Uveitis in London and Iowa. Ophthalmologica 1984;189:36-40.

41. Yang $\mathrm{P}, \mathrm{Zhang} \mathrm{Z}$, Zhou $\mathrm{H}$, et al. Clinical patterns and characteristics of uveitis in a tertiary center for uveitis in China. Curr Eye Res 2005;30:943-8.

42. Kump LI, Cervantes-Castaneda RA, Androudi SN, Foster CS. Analysis of pediatric uveitis cases at a tertiary referral center. Ophthalmology 2005;112:1287-92.

43. Pivetti-Pezzi P. Uveitis in children. Eur J Ophthalmol 1996;6:293-8.

44. Tugal-Tutkun I, Havrlikova K, Power WJ, Foster CS.Changing patterns in uveitis of childhood. Ophthalmology 1996;103:375-83.

45. Heiligenhaus A, Niewerth M, Mingels A, et al. Epidemiology of uveitis in juvenile idiopathic arthritis from a national paediatric rheumatologic and ophthalmologic database [German]. Klin Monatsbl Augenheilkd 2005;222:993-1001.

46. Paivonsalo-Hietanen T, Tuominen J, Saari KM. Uveitis in children: population-based study in Finland. Acta Ophthalmol Scand 2000;78:84-8.

47. Bundesamt S. Zahlen und Fakten ueber die Bundesrepublik Deutschland. Datenreport 2006:28. 